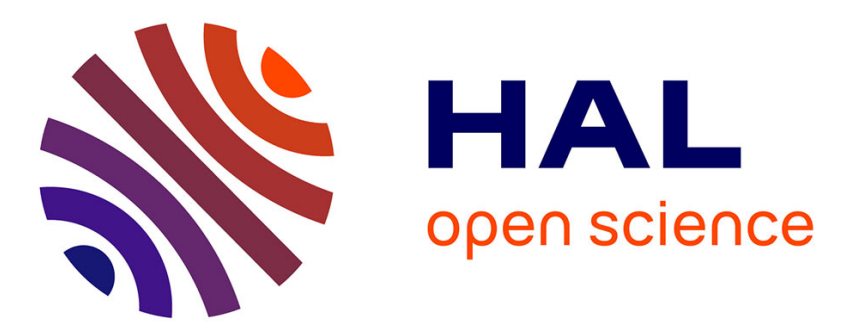

\title{
Ecosystem-based adaptation to climate change: What role for policy-makers, society and scientists?
}

\author{
Raffaele Vignola, Bruno Locatelli, Celia Martinez, Pablo Imbach
}

\section{To cite this version:}

Raffaele Vignola, Bruno Locatelli, Celia Martinez, Pablo Imbach. Ecosystem-based adaptation to climate change: What role for policy-makers, society and scientists?. Mitigation and Adaptation Strategies for Global Change, 2009, 14 (8), pp.691-696. 10.1007/s11027-009-9193-6 cirad-00699340

\section{HAL Id: cirad-00699340 http://hal.cirad.fr/cirad-00699340}

Submitted on 20 May 2012

HAL is a multi-disciplinary open access archive for the deposit and dissemination of scientific research documents, whether they are published or not. The documents may come from teaching and research institutions in France or abroad, or from public or private research centers.
L'archive ouverte pluridisciplinaire HAL, est destinée au dépôt et à la diffusion de documents scientifiques de niveau recherche, publiés ou non, émanant des établissements d'enseignement et de recherche français ou étrangers, des laboratoires publics ou privés. 
Ecosystem-based adaptation to climate change:

what role for policy-makers, society and scientists?

Raffaele Vignola, Bruno Locatelli, Celia Martinez, Pablo Imbach

Accepted version of: Vignola R., Locatelli B., Martinez C., I mbach P., 2009. Ecosystem-based adaptation to climate change: what role for policy-makers, society and scientists? Mitigation and Adaptation of Strategies for Global Change 14: 691-696. doi: 10.1007/s11027-0099193-6

R. Vignola $(*)$, C. Martinez, P. Imbach: CATIE, Climate Change Program, Turrialba, Costa Rica

B. Locatelli: CIRAD UPR Forest Policies, Montpellier, France; CIFOR ENV, Bogor, Indonesia

(*) R. Vignola, ETH Zurich, Institute for Environmental Decisions, Natural and Social Science Interface, 8092 Zurich, Switzerland, e-mail: rvignola@catie.ac.cr

\section{Abstract}

In developing countries where economies and livelihoods depend largely on ecosystem services, policies for adaptation to climate change should take into account the role of these services in increasing the resilience of society. This ecosystem-based approach to adaptation was the focus of an international workshop on "Adaptation to Climate Change: the role of Ecosystem Services" held in November 2008 in Costa Rica. This article presents the key messages from the workshop.

\section{Keywords}

Adaptation to climate change. Ecosystem services. Policy-science-society dialogue 


\section{I ntroduction}

An international workshop on "Adaptation to Climate Change: the role of Ecosystem Services" was held in November 3-5, 2008 in the International Centre for Tropical Agriculture Research and Higher Education (CATIE) in Turrialba, Costa Rica. The 80 participants came from 24 countries (mostly Latin American) and 56 institutions (local communities, NGOs, scientific organizations, government agencies, public and private firms, and international agencies for cooperation) to discuss the role of ecosystem services in adaptation to climate change.

While most developing countries' economies depend largely on natural resources and ecosystem services, the capacity of ecosystems to provide services to sectors of the society is pressured by land use change and climate change. As adaptation is needed for the sectors of society facing the impacts of climate change, it is necessary to consider the vulnerability and role of ecosystems in sustained provision of ecosystem services to these sectors.

The aim of this article is to present the key messages that the participants discussed during the workshop. These key messages are targeted at the stakeholders that can design and implement ecosystembased adaptation (EBA). We define ecosystem-based adaptation as the adaptation policies and measures that take into account the role of ecosystem services in reducing the vulnerability of society to climate change, in a multi-sectoral and multi-scale approach. EBA involves national and regional governments, local communities, private companies and NGOs in addressing the different pressures on ecosystem services, including land use change and climate change, and managing ecosystems to increase the resilence of people and economic sectors to climate change. The concept of EBA has emerged recently in the international climate change arena, with countries (e.g., Colombia, Sri Lanka), groups of countries (e.g., the African Group) and observers (e.g. the International Union for Conservation of Nature) addressing EBA in their submissions to the United Nations Framework Convention on Climate Change. 


\section{Content of the workshop}

The workshop included seven sessions. The first session aimed at updating participants on the main concepts and issues related to ecosystem services, adaptation to climate change, and EBA. The second session aimed at communicating results of scientific studies related to the vulnerability of ecosystems and ecosystem services in Latin America. Discussion topics addressed different dimensions of ecosystem vulnerability: exposure (climate change scenarios), sensitivity (e.g. the impacts of climate change on protected areas, hydrological ecosystem services or forest fires), and adaptive capacity (e.g. the role of landscape connectivity in eco $\neg$ system adaptation). The third session addressed the role of ecosystem services (e.g. hydrological services for sectors depending on water, such as drinking water and hydropower production).

During the fourth session, attendees reviewed experiences of policies and measures for adaptation at local, national and regional levels. Even though the impacts of climate change and the role of ecosystem services are uncertain, no-regret policy responses can benefit both climate change adaptation and sustainable ecosystem management. The fifth session aimed at exploring communication strategies regarding adaptation to climate change. Establishing an efficient dialogue between scientists, decision makers and civil society is challenging but necessary for EBA. This dialogue should start at the stage of research design and be pursued until the communication of research results and uncertainties.

During the sixth session, financial mechanisms for adaptation or for the management of ecosystem services were reviewed. Innovative financial mechanisms are needed for these processes, but remain challenging because of the complexity of evaluating adaptation costs and benefits, and the sensitivity of political negotiations related to international adaptation finance. The seventh session was aimed at sharing experiences of public and private initiatives of ecosystem management and conservation. As these initiatives are seldom explicitly linked with climate change adaptation, their role in reducing the vulnerability of ecosystems and society needs to be further analyzed.

The participants presented a wide array of perspectives and experiences related to ecosystem services and adaptation to climate change in Latin America, including community management, payment for ecosystem 
services, and insurance schemes. These experiences allowed participants to discuss crucial issues such as the need for institutional changes for adaptation, a better understanding of uncertainties and strategies to cope with them, improved dialogue between scientists and decision makers, and strengthened linkages between sectors and scales, from local to global levels.

At the end of the workshop, the participants worked in groups to elaborate key messages directed at three groups of stakeholders in EBA: (1) national policy-makers (2) local communities, private sector and others members of civil society, (3) scientists (Fig. 1).

\section{Key messages for national policy-makers}

Mainstream adaptation and ecosystem services into national policies Ecosystem degradation and vulnerability to climate change are development issues rather than strictly environmental problems. As the loss of natural capital and the associated vulnerabilities are a threat for sustainable development, national development policies should integrate ecosystem management and adaptation to climate change. Multisectorial and cross scale approaches are needed for mainstreaming both adaptation and ecosystem services into policies. Policy-makers should create and enforce linkages between ecosystem managers and vulnerable sectors benefiting from ecosystem services. Moreover, education and outreach policies should raise societal awareness about the relevance of ecosystem services and adaptation for sustainable development.

Develop innovative funding

Because of market failures, current regulations fail to conserve ecosystem services that are valuable for society. Thus, sectors benefiting from ecosystem services should be involved in funding ecosystem management or conservation. Payment for Ecosystem Services (PES) is an innovative mechanism being developed in several Latin American countries in both governmental and private initiatives. PES can complement international adaptation funding sources in cases where the users of ecosystem services are willing and able to provide resources for protecting these services. The challenge for policymakers is to create an institutional environment that facilitates agreements between users and providers of ecosystem services. 
Influence international policies

International negotiations on development and environmental issues can influence national policies on adaptation and ecosystems and thus EBA design. Policy-makers should therefore ensure that the outcomes of negotiations in this arena include adequate consideration of ecosystem services that are priorities for their national development and adaptation. To enforce their positions in these negotiations, it is strategically important that policy-makers strengthen their understanding of the challenges implied in designing and implementing EBA. This might be especially relevant in the context of the negotiations defining the terms of reference and the management of the Adaptation Fund where investment priorities are defined.

Strengthen the links between adaptation and mitigation

Mitigation instruments, such as the Clean Development Mechanism or the currently discussed REDD (Reduction of Emission from Deforestation and Forest Degradation) can provide benefits for both mitigation and adaptation, as they contribute to conserving and restoring ecosystem services. However, some concerns have been raised about the potential negative impacts that some mitigation projects may have on local development and biodiversity. Thus policymakers should try to foster synergies between mitigation and adaptation by developing and applying guidelines or standards for mitigation projects. These standards could provide guidance to mitigation project developers willing to address adaptation and enable policymakers or donors to assess the contribution of mitigation projects to adaptation.

Interact with local communities

Local communities are important decision-makers in adaptation and ecosystem management. National policymakers should empower local and indigenous communities to facilitate adaptation processes that take traditional knowledge into account. EBA policies should recognize the diversity of local situations and create a facilitating environment for effective local adaptation and ecosystem management. Policies should also promote environmental education for promoting EBA in local communities.

Interact with scientists

Understanding climate change impacts and vulnerability is a complex task, and technical expertise is required to understand and interpret the 
results of scientific studies. It is therefore important that, for building no-regret policies, policy-makers interact with scientists to take into account uncertainties inherent in climate change studies. Policy-makers should create institutional arrangements and funding sources to facilitate the development and use of relevant social and natural science knowledge into policy processes.

\section{Key messages for communities, local actors and others members of civil society}

The following messages are addressed to the variety of stakeholders that manage ecosystems, implement adaptation, or use ecosystem services, such as local communities, the civil society and the private sector.

Define and implement adaptation

Even though national policies influence local processes, adaptation eventually happens locally. Local actors have the responsibility to promote EBA, given their direct interest in ecosystem health and provision of services. Communities should design and implement strategies for ecosystem-based adaptation as part of their local resource planning. Civil society and communities should increase their capacity to negotiate and establish equitable partnerships with a variety of actors (public and private) acting at different scales of decisions. NGOs can play a role in strengthening indigenous populations in protecting their rights and values in the design of adaptation plans.

Reward ecosystem service providers

Local communities, civil society and private actors should reward actors that conserve or restore ecosystem services. This would enable restoring services, or preventing future land use changes and loss of services. Innovative mechanisms, such as PES, may be an important component of ecosystem-based adaptation.

Interact with policy makers

Policy makers set the institutional context in which ecosystem-based adaptation can take place. The interests, obstacles and capacities of local communities, however, are not always reflected in national and local policies. A key role for civil society is then to empower the capacity of local actors to participate in policy-making at both local and national 
levels. Building capacity and opening spaces for participation in policy making can be a way to achieve these goals.

Interact with scientists

Research on ecosystems services and how they can reduce societal vulnerability to climate change is a relatively new field characterized by complexity and uncertainty. In this context, local knowledge on ecosystems and their management should be respected and is crucial for improving scientists' understanding and their capacity to support design of appropriate responses. In this respect, interaction with social scientists is important given their expertise on integrating different knowledge-systems into collaborative efforts. Local communities and civil society are thus called to play a more active role, getting involved in field research and informing scientists on observed changes and local adaptation, and scientists should adapt their methods to use these resources. In addition, private sectors could also finance science, as they also could benefit from new scientific knowledge on adaptation and ecosystem services.

\section{Key messages for scientists}

Quantify and value ecosystem services

Several international scientific initiatives such as the Millennium Ecosystem Assessment have acknowledged the relevance of ecosystem services for human wellbeing. However, more evidence is needed on the role of ecosystem services in reducing the vulnerability of society, as well as the costs and benefits of conserving ecosystem services, in the context of climate change. Quantification and spatial prioritization of ecosystem services for adaptation are also needed for adaptation.

Evaluate uncertainties

Ecosystem services and climate change impacts assessments deal with complexity and uncertainty; therefore, their recognition and evaluation is essential for designing adaptive approaches to EBA. Impact or vulnerability studies should always include an analysis of sensitivity, for instance, using different models and different climate scenarios. In an adaptive process, uncertainty analysis also enables the identification of which variables are uncertain and determinant in explaining vulnerability 
to climate change. These variables can be transformed into indicators for monitoring trends in the field.

Work at local scales

Many climate change impact studies or vulnerability assessments show results on regional and global scales, providing a broad view that seldom helps interested parties to design local adaptation. For instance, EBA requires identifying the flow of ecosystem services in local landscapes, as a tool for determining land uses that may provide ecosystem services relevant to the adaptation of society. Thus, more research is needed to address scientific issues related to EBA at a local scale. In addition, social scientists have an important role to play in understanding local social processes relevant for adaptation and ecosystem conservation.

Communicate results to non-scientists

Scientists should devote substantial efforts in communicating research results to non-scientists, such as local NGOs, public administration and the media, in order to increase their capacity to influence the implementation of EBA. Strategic alliances with experts from communication sciences should be considered as a key component of research projects on EBA.

Interact with local communities and private sector

Scientists studying climate change impacts and the design of EBA measures are called to work closely with local communities and the private sector in order to understand local processes of adaptation and ecosystem management. Scientists should also involve local communities and private sectors from the early stages of research design, so that scientific work and results can serve local EBA design and implementation.

Interact with policymakers

Scientists producing knowledge on climate change impacts and EBA measures should ensure that results are communicated in a way that is relevant to policy-makers. At the local and national levels, scientists should participate, as one of the stakeholders, in policy design process, including problem identification, strategy formula $\neg$ tion, selection of policy options, monitoring and evaluation. At global level, scientists can play an important advisory role to national policy-makers who 
participate in international negotiations related to adaptation and possibly to EBA.

\section{Conclusions}

Increasing attention has been paid to the complex interactions between human and environmental systems, especially regarding the conservation and management of ecosystem services. However, the role of ecosystem services in supporting adaptation to climate change is a relatively new issue in the scientific arena, and even more so in the policy arena. In order to promote the role of ecosystem services in societal adaptation to climate change, it is important that a variety of actors, such as policy-makers, scientists and civil society, are actively involved in accordance with their mandates. The key messages presented in this article are not only relevant for Latin America but are valid also for other regions, especially where people depend strongly on natural resources.

\section{Acknowledgments}

The authors thank the participants of the workshop whose messages and ideas were used in this report and anonymous reviewers for their useful contributions. The workshop was realized within the framework of the project "Tropical Forests and Climate Change Adaptation" (TroFCCA), executed by CATIE and CIFOR and funded by the European Commission under contract EuropeAid/ENV/2004-81719. The contents of this document are the sole responsibility of the authors and can under no circumstances be regarded as reflecting the position of the European Union. 
Fig. 1 Key messages to stakeholders related to ecosystem-based adaptation (EBA)

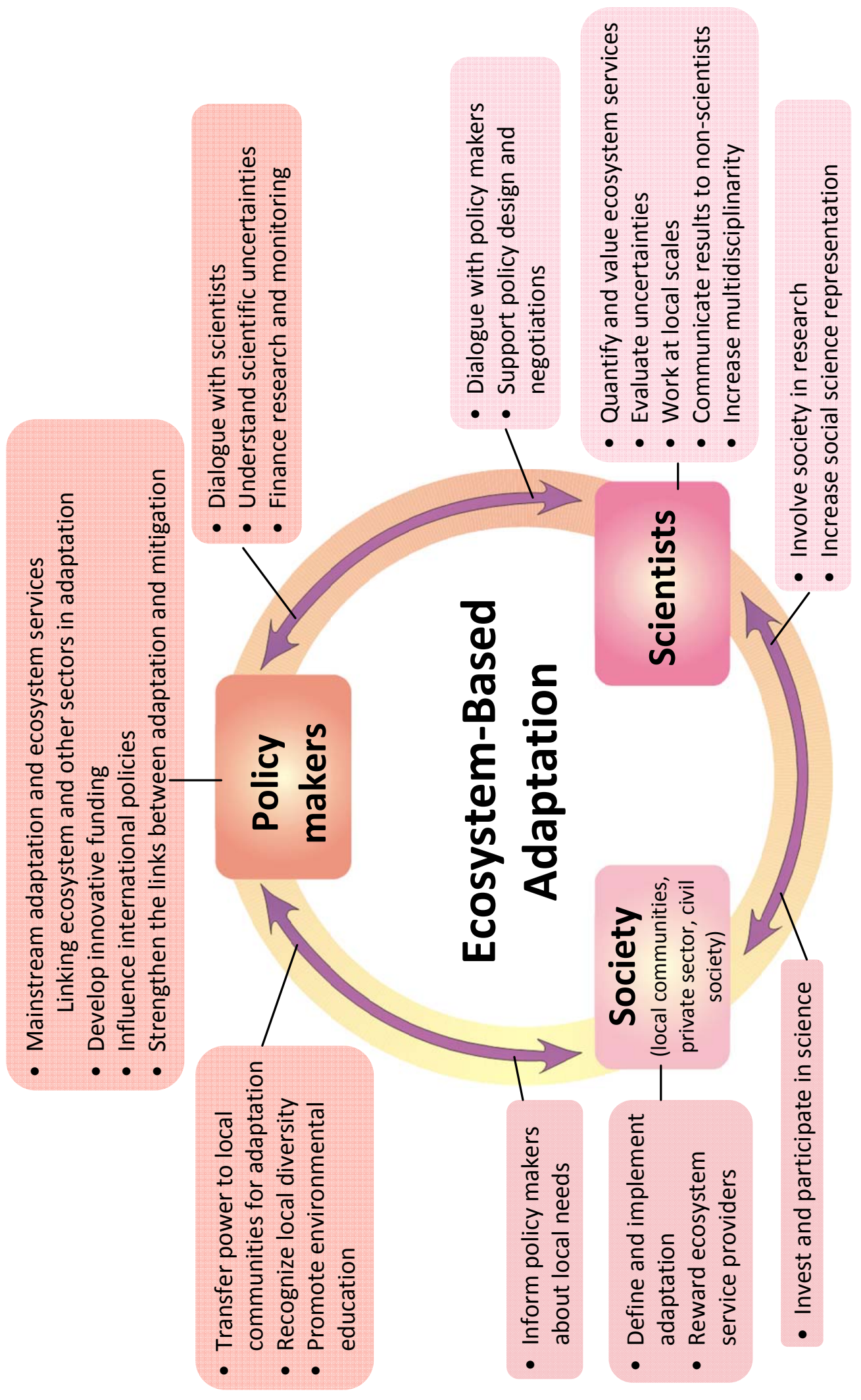

